\title{
O ensino do algures e do outrora: apontamentos sobre 0 ensino da Geografia e da História a partir das obras de Yves Lacoste e Marc Ferro
}

Resumo: 0 artigo decorre de um projeto de pesquisa que investiga as relações entre o ensino da história e da geografia e o uso social e político da memória coletiva e dos espaços. Este estudo tem por objetivo discutir o trato dessa questão nas obras de Yves Lacoste e Marc Ferro. Parece possível afirmar que, para esses autores, o controle da memória histórica e do conhecimento dos lugares foi compreendido como uma dimensão fundamental para garantir o poder político de determinados grupos sociais.

\section{Somewhere and before now teaching: indications about the History and Geography teaching from Yves Lacoste and Marc} Ferro works.

\footnotetext{
Abstract: This article derives from a research project investigating the relations between the history and geography teaching and the social and political use of the collective memory and the places. This study aims at debating the dealing of this issue in the works of Yves Lacoste and Marc Ferro. It seems possible to say that, for this authors, the controlling of the historic memory and of know about of the places was comprehended as an essential dimension in order guaranteeing politic power of the determined social groups.
}

André Luiz Paulilo*

*Professor da Escola de Educação da Universidade Municipal de São Caetano do Su.

Palavras-chave: Ensino de História e de Geografia; Metodologia do Ensino; Yves Lacoste e Marc Ferro.

Key-words: History and Geography teaching; Methodology of the Teaching; Yves Lacoste and Marc Ferro. 
Em fins da década de 1970 e início dos anos 1980, as traduções para a língua portuguesa das obras de Marc Ferro (1983) sobre a história contada para as crianças e de Yves Lacoste (1977) a respeito da geografia ensinada pelos professores contribuíram para a discussão da História e da Geografia como disciplinas escolares no Brasil. A preocupação daquele momento em repensar as proposições teóricas-metodológicas do ensino do passado e dos conhecimentos relativos à ocupação do espaço afirmou tendências críticas a uma educação prontamente identificada com a ditadura, a opressão e a negação de direitos.

Nesse período, o materialismo histórico e a organização do ensino por temas e problemas constituíram os principais caminhos para a discussão e a produção da Geografia e da História. Por um lado, as discussões em torno das condições do ensino de Geografia, das críticas referentes aos conteúdos veiculados por essa matéria e aos fundamentos da ciência geográfica incorporaram as análises de Yves Lacoste sobre o comprometimento da geografia do professor e o caráter estratégico do saber sobre o espaço obliterado por esta geografia. Segundo Pontuschka, Paganelli e Cacete (2007, p. 54) a obra de Lacoste desencadeou polêmicos debates entre geógrafos de diferentes gerações e correntes de pensamento no Brasil. Por outro lado, as reflexões de Marc Ferro (1983) contribuíram para a compreensão dos artifícios da história para construir a identidade e a situação de fato das sociedades através do tempo. Em Ferro, a necessidade de conhecer a história e de reconstruí-la sobre novas bases pôs à prova a realidade ou a legitimidade da história que se conta às crianças ou que se oferece como espetáculo nos filmes, propagandas e comemorações.

Em muitos sentidos, foram leituras que se complementaram nos debates surgidos no final do período da ditadura militar no Brasil tanto a história dos dominados que Ferro vasculha quanto a geografia das dominações que Lacoste denunciou. Os questionamentos de então sobre os rumos do ensino da Geografia e da História procuravam dar voz e lugar a diferentes sujeitos e repercutiam as lutas que a partir dos anos 70 pressionavam pela redemocratização da sociedade brasileira. Portanto, as condições sociais em que apareceram as traduções de La Géographie, ça sert, d' abord, à faire la guerre e de Comment on raconte l'histoire aux enfants à travers le monde entier eram de contestação política e revisão da função ideológica e dos fundamentos metodológicos da Geografia e da História no ensino do país. Naquele momento, sua apropriação nas discussões relativas ao conhecimento que vinha sendo ensinado nas escolas e às novas tendências e avanços nos campos historiográficos e geográficos tiveram a ver com a preocupação do conteúdo político de ambas as disciplinas e seus papéis na formação dos cidadãos.

Voltar a discutir tais textos atualmente não deve ser visto como uma nova tentativa de resposta aos mesmos desafios e problemas de quando eles surgiram. Em certo sentido, o retorno do ensino da História e da Geografia ao currículo escolar tornou mais autóctone e disseminada a reflexão a respeito do significado político das escolhas temáticas e de método nessas disciplinas. Assim, trata-se de repensar, em face das atuais propostas curriculares, os esquemas de percepção que as obras de Ferro e Lacoste consagraram ao abordar os instrumentos de controle ideológico do ensino da História e da Geografia. Por outro lado, algumas questões, como as da exploração de gêneros discursivos e linguagens nas diferentes áreas do conhecimento, estão apenas agora se abrindo para a pesquisa. O que se segue, então, não lavra novos campos de reflexão sobre as metodologias do ensino da História e da Geografia e nem pretende resgatar a missão que os intelectuais confiaram aos professores dessas disciplinas entre os anos de 1970 e 1980. Aqui, o esforço vai em direção da discussão acerca dos usos que a História e a Geografia sofrem na sala de aula e dos seus instrumentos de 
manipulação. Nesse sentido, a análise de A manipulação da história no ensino e nos meios de comunicação e de A geografia serve antes de mais nada para fazer a guerra permite questionar algo das vivências que o ensino das humanidades proporciona na escola.

\section{A história dos dominados e a geografia das dominações}

As manobras para a história legitimar as dominações e para dar eficácia policial e militar às estratégias de organização do espaço social, econômico e político das cidades são o foco da crítica aos saberes histórico e geográfico na época em que ambas as obras foram escritas. Em fins dos anos 70 e início dos 80, a historiografia buscou por interpretações que levassem em conta diferentes grupos sociais e seus pontos de vista. Os estudos e ensaios de Jacques Le Goff, Philipe Áriès, Michel Certeau, Jean Chesnaux, Emmanuel Le Roy Ladurie e, entre outros, 0 próprio Marc Ferro puseram em relevo as falhas que ameaçam a coesão frágil das sociedades e as tensões entre indivíduos e grupos. Igualmente, a Geografia praticada por Yves Péchoux, Jean-Michel Brabant e Michel Riou, por exemplo, que é também a de Yves Lacoste (1976, 1977 e 1985), discutiu o problema da estratégia e da ideologia na análise geográfica por meio da abordagem das formas de espoliação do terceiro mundo e da sua problemática ideológica.

Nas perspectivas de então, a simpatia ao marxismo ainda definia um viés da crítica social tanto para a historiografia quanto para o pensamento geográfico. Sobretudo, as categorias marxistas de análise da sociedade suscitaram na teoria social uma profícua conceituação das relações de poder de cujos princípios historiadores e geógrafos também se valeram para denunciar e combater as estruturas de exploração do sistema capitalista. Assim, termos como hegemonia (GRAMSCI, 1968) e violência simbólica (BOURDIEU, 2000) e as noções de desenvolvimento e subdesenvolvimento (FURTADO, 1961; GUNTER-FRANK, 1974) operavam uma oposição entre classes sociais ou países dominantes e dominados cujas relações são predominantemente analisadas do ponto de vista da exploração.

Não obstante a contribuição das categorias marxistas de compreensão social que as discussões de Ferro e Lacoste mostram prezar e, inversamente, a utilidade das suas obras para o debate político da época, A manipulação da história no ensino e nos meios de comunicação e A geografia serve antes de mais nada para fazer a guerra suspeitam dos apanágios da formalização. Ferro e Lacoste propuseram, respectivamente, uma história dos dominados e uma geografia das dominações num momento de contestação das categorias marxistas de análise do poder. Suas obras resultam do abalo das grandes conceituações que nos anos 1970 deu direito de cidadania às ideias de Foucault, Norbert Elias, Bourdieu e de toda uma plêiade de autores que vinham construindo instrumentos teóricos próprios. As questões tratadas por Ferro e Lacoste ganham mais sentido nessa conjuntura de diálogo em que os historiadores e geógrafos entretiveram entre suas disciplinas e com a economia ou a sociologia. Assim, as vias que então se desenharam para a reflexão epistemológica da História e da Geografia tornaram profícuo pensar o ensino dessas disciplinas como instrumentos de poder.

A decisão de Marc Ferro publicar um livro sobre as versões da história que diferentes povos aprendem não escapou aos custos de recortes difíceis e de uma séria desigualdade de tratamento. No entanto, reunir a visão de passado própria das quinze a vinte visões de passado das sociedades que constam do livro, produzindo um itinerário de estudo da identidade de cada história nacional, foi, mais que uma estrita operação historiográfica, um decidido esforço de compreensão do seu próximo. 0 próprio autor anuncia o projeto como um estudo dos azares

Geografia Ensino \& Pesquisa, v. 15, n.3, p. 113-128, set./dez. 2011

André Luiz Paulilo 
históricos de cada nação e das variações de sua historiografia (FERRO, 1983, p. 15). Nesse sentido, o título que a tradução brasileira dá do original faz do próprio livro uma peça da luta política. Apesar da inteira adequação da apropriação realizada à conjuntura de contestação que vivia o Brasil, os termos "manipulação" e "dominados" reduzem o intuito do empreendimento aos seus aspectos políticos, numa chave marxista de interpretação. As questões historiográficas que a obra desdobra e a dimensão cultural e social do uso político da história escapam do título, mas não da leitura. Preocupou Marc Ferro (1983, p. 11) o passado que se tornou alvo do confronto entre Estados e Nações, entre culturas e etnias. Ao fundo das disputas pelo controle da história de uma coletividade própria, importou-lhe decodificar os modos de açambarcamento da verdade histórica por alguns, as estratégias de produção da história e os artifícios do seu controle. Além da política, Ferro percebe nessas iniciativas as motivações culturais e uma espécie de necessidade humana de reabilitar o próprio orgulho perante os outros.

Já Yves Lacoste, com a publicação de A geografia serve antes de mais nada para fazer a guerra, discute a utilidade da Geografia para o poder estabelecido. Nesse aspecto, seu estudo da omissão da Geografia dos professores em relação às práticas imperialistas, às políticas de reordenamento do território ou em relação às estruturas multinacionais de exploração é conseqüente quanto aos limites do marxismo como instrumento de compreensão dos conflitos sociais. Lacoste (1977, p. 76-77) compreende bem que o marxismo não avança nos métodos de análise do espaço e que muitas vezes serviu para iludir os problemas teóricos específicos da Geografia. Sua preocupação com a análise das diferenciações espaciais e com a maior eficácia das ações militantes percebe os fenômenos geográficos como dados estratégicos fundamentais tanto para os comandantes militares e dirigentes das grandes firmas multinacionais quanto para os movimentos populares. A Lacoste (1977, p. 127) interessou mostrar que os locais onde os cidadãos habitam ou trabalham são frentes de disputa em cujo espaço atuam ao fixar residência e se deslocar, quando lutam e opõem resistências, enfim, enquanto apropriam-se de um lugar. Sobretudo, são dos raciocínios para dominar o espaço e agir, dos níveis de análise e conceituação do espaço, do processo de tecnocratização e açambarcamento desses raciocínios e análises por uns poucos e do uso político disso tudo de que trata Lacoste neste livro. Ao sublinhar o papel da Geografia como instrumento de poder político e militar, sua abordagem adverte acerca dos compromissos dos quadros conceituais dessa disciplina com a eficácia das formas de autoridade.

Verifica-se a convergência de perspectivas que há entre os esquemas de percepção de Lacoste e Ferro. Ressaltam as difíceis questões de interpretação e representação que envolvem tanto a historiografia como a geografia e indicam o sistema de crenças cuja eficácia depende do controle do passado ou das relações espaciais. 0 grau de atenção dedicado por ambos os autores às funções e operações de sentido desempenhadas por um saber especializado sugere que ainda atualmente a Geografia e a História servem para instrumentalizar o poder estabelecido. Por meio de omissões, rearranjos e mistificações ou de um mero alheamento das práticas sociais produz-se dissimulação e mentira em vez da verdade científica. Além disso, as reflexões de Ferro (1983) e Lacoste (1977) concordam que o ensino é uma maneira política de manter ou modificar a apropriação dessas dissimulações e mentiras e os saberes e poderes que elas trazem consigo. Observar a relevância especial da educação para conhecer ao mesmo tempo a identidade e a situação de fato das sociedades de um determinado lugar através do tempo foi salutar para a compreensão de todo um sistema de manipulações e subterfúgios. Assim como Lacoste critica aquilo que na escola impede uma apreensão eficaz das características espaciais das realidades econômicas, sociais e políticas, Ferro trata do que torna 
o ensino incapaz de superar os estereótipos da história ocidental. Em cada um desses estudos, a ênfase sobre o conflito entre as tentativas de encontrar soluções universais para os problemas humanos e as necessidades ou a lógica da situação é exemplo da contribuição que deram para pensar as certezas militantes e as ilusões do ensino da Geografia e da História.

\section{As funções terapêuticas e militantes do ensino da História e da Geografia}

Em seu livro sobre a instrumentação que a Geografia assegura aos estados-maiores e grandes corporações, Yves Lacoste $(1977$, p. 6) denuncia as funções essenciais do palavreado da geografia escolar e universitária. Por um lado, apresentar a nação onde vivemos como se tratasse não de uma construção histórica, mas de um conjunto espacial engendrado pela natureza tem sido prática invariavelmente ligada ao enobrecimento e à edificação do sentimento nacional. Para Lacoste (1977, p. 33), não é por acaso que os argumentos geográficos têm muito peso tanto no discurso político como também na expressão popular da idéia de Pátria. Sobretudo nos países de passado colonial, avalia Lacoste, a instauração do ensino da Geografia não teve por fim difundir um instrumento conceitual que permitisse pensar o espaço, mas tão só naturalizar fisicamente os fundamentos da ideologia nacional. Nesse sentido, parece-lhe que 0 ensino da Geografia faz passar um saber estratégico, militar e político, por um discurso pedagógico e científico inofensivo. Por outro lado, é essa sua função mistificadora que ilude 0 papel da Geografia como instrumento de poder e, segundo Lacoste (1977, p. 7), torna a geografia dos professores a única de que convém falar. 0 raciocínio de tipo geográfico permite uma ação eficaz sobre o espaço que, negligenciado durante a formação escolar, tornou-se monopólio de uma minoria dirigente que dele sabe se servir. Assim, há no açambarcamento desse saber por parte daqueles que detém poder para dirigir, dominar ou explorar um território 0 controle de informações que dizem respeito a todos os cidadãos. Resistir a isso para Lacoste (1977, p. 108) implicaria varrer a indiferença geral face à Geografia e denunciar a sua importância como saber estratégico para a luta política.

O particular interesse de Marc Ferro pela função terapêutica e militante da História é do mesmo tipo que o da crítica de Lacoste acerca do discurso pedagógico e científico da Geografia. A expiação dos problemas que são atuais por meio da História é prática comum do cientificismo e das metodologias úteis ao disfarce ideológico do passado segundo Ferro (1983, p. 12). Lembrando Croce, afirma que a História coloca mais os problemas do seu tempo do que os da época que se propõe estudar e indica a função terapêutica da História na glorificação do Cristo Rei na Espanha franquista, da Nação e do Estado na República francesa, do Partido Comunista na União Soviética ou na China e dos grandes impérios do passado africano na história ensinada às crianças negras do continente. Inversamente, contar a história dos males e tragédias exerce a mesma função terapêutica para povos como os Armênios. Ferro (1983, p. 13) se preocupou igualmente com a função militante da História. Das manipulações então praticadas na União Soviética à passagem da ideologia do melting-pot para a ideologia da salad bowl nos Estados Unidos, mostra que o ensino da História não só foi o veículo de certezas militantes como a marca da consciência coletiva de cada sociedade. Assim, também as narrativas e crenças acerca das proezas do herói Shivaí, na Índia, das desventuras de Yoshitsunê, no Japão, das aventuras de Chaka, rei dos Zulus, ou de Joana d'Arc na França configuram meios para cada uma dessas culturas conservarem sua identidade através da História. Marc Ferro teve claro que essa dupla função da História é exercida independentemente da vocação científica da

Geografia Ensino \& Pesquisa, v. 15, n.3, p. 113-128, set./dez. 2011

André Luiz Paulilo 
disciplina. Por um lado, portanto, o pesado contencioso do passado colonial como a memória dos genocídios ou a má consciência de não possuir um Estado livre alimentam o apego pela história, pela cultura e pela pátria perdida ou pelo seu esquecimento. Por outro lado, a história que os numerosos grupamentos humanos elaboram em oposição aos seus vencedores, a sua segmentação de acordo com as exigências dos cidadãos ou a acomodação política do seu sentido possuí a clara função militante de exprimir ou legitimar uma política, uma ideologia, um regime.

$\mathrm{Na}$ época em que foram traduzidos no Brasil, os livros de Lacoste e Ferro consolidaram a preocupação com o conteúdo político da Geografia e da História na formação do cidadão. $\mathrm{Na}$ Geografia as contribuições de Lacoste para o ensino da disciplina ocupam um lugar mais central que as de Marc Ferro na História. Para Ruy Moreira (1992, p. 8), Yves Lacoste teve o papel de dar impulso inicial às reflexões para a renovação da Geografia no Brasil ao analisar o comprometimento político da "geografia do professor" e o caráter estratégico do saber sobre 0 espaço. Em especial, as reflexões de Lacoste foram discutidas nas principais obras de referência sobre o ensino da Geografia no início da redemocratização do país. Principalmente Ariovaldo Umbelino de Oliveira (1988) e José William Vesentini (1989) organizaram títulos para coleções voltadas ao magistério em que se discutiam o alcance das ideias de Lacoste. Já a presença de Marc Ferro na produção sobre o ensino da História do Brasil e na sua historiografia é muito mais modesta. Não obstante as posições do autor refletirem as propostas da nova história francesa para se conhecer a História e reconstruí-la sobre bases mais experimentais, foi preferencialmente através das discussões das perspectivas historiográficas abertas por Jacques Le Goff, Paul Veyne, François Furet e Michel de Certeau entre outros que se renovou a reflexão a respeito do ensino de História. Outro importante conjunto de pesquisas apropriadas pelos debates acerca do ensino da História no Brasil provinha da nova história social inglesa, sobretudo discutida a partir das traduções das obras de Hobsbawn e Thompson. Assim, as principais iniciativas para repensar o ensino da História entre as décadas de 80 e 90 do século passado articularam-se em torno dos novos objetos e das novas abordagens construídas por uma nova historiografia francesa e inglesa.

Nesse sentido, são exemplares os volumes então organizados por Marcos Silva (1984), Ernesta Zamboni (1984), Jaime Pinsky (1988), Circe Bittencourt (1997) e pela ANPUH (Revista Brasileira de História n. ${ }^{\circ} 9, n^{0} 13$ e n. ${ }^{0} 19$ ) sobre a História e o seu ensino. Os estudos que foram reunidos nesses volumes submeteram a diversos questionamentos as vivências em sala de aula. Tanto realizaram diversas experiências no sentido de preservar a autonomia dos professores quanto foram o resultado de importantes reflexões em torno de o que e como ensinar. Tendo em vista uma nova historiografia que então se desenvolvia na universidade, foram esboçadas alternativas no ensino/aprendizagem da História.

Uma amostragem do mesmo tipo para a área do ensino da Geografia mostra igual proficuidade das discussões. As coletâneas organizadas por Ariovaldo U. de Oliveira (1988), José William Vesentini (1989; 2005), João Ruas (1993) e Ana Fani Alessandri Carlos (1999, 2007), mas também uma crescente produção de monografias sobre o ensino da Geografia informa sobre a variedade de preocupações e metodologias atualmente discutidas. Por meio do desenvolvimento de estudos sobre o ensino dos solos e dos recursos hídricos, a questão das projeções cartográficas no ensino de geografia e a reflexão a respeito da utilização da arte, da música, dos quadrinhos e do audiovisual abriram-se perspectivas para uma construção sempre renovada da Geografia ensinada. Algo desses estudos tem ganhado espaços editoriais, como 0 atestam, por exemplo, as obras publicadas por Marcia Resende (1986), Ruy Moreira (1987), 
Rosângel D. de Almeida e Elza Y. Passini (1989), Vânia Vlach (1991), José Vesentini (1992) e Lana de Souza Cavalcanti (1998). Outro tanto deles, desenvolvem-se no âmbito de realização das equipes de pesquisa sediadas nos departamentos de geografia das universidades, como no caso do Laboratório Ensino e Material Didático (LEMADI-USP) e do DocumentAGRO.

Em meio à variedade das abordagens e metodologias desenvolvidas nas discussões dessas séries de pesquisas e ensaios, as preocupações com o conteúdo político de ambas as disciplinas recrudesceram-se, consolidando uma exigência dos estudos sobre 0 ensino da História e da Geografia. Sugestão ousada à época, vislumbrar no ensino dessas disciplinas as práticas, os interesses e as motivações dos poderes econômicos ou políticos hoje é quase uma perspectiva ortodoxa de análise. Indica-o a diversidade de interpretações que resultou da variedade das escalas de análise e da atenção aos vários esquemas eurocêntricos de abordagem pelos quais foi percebido o passado e o presente do Brasil. A insistência com que se debate 0 ensino da diversidade cultural do país e do seu ordenamento territorial ainda reflete as discussões de Ferro e Lacoste acerca das funções essenciais da História e da Geografia escolares. Ariovaldo (1988) e Vesentini $(1989$; 1992) contribuíram nesse sentido para revelar a operacionalidade da Geografia e do seu ensino em publicações voltadas ao magistério. Seus estudos sublinharam o papel ideológico da Geografia escolar, sua falsa neutralidade e eficácia na reprodução das dominações como, entre outros, também fizeram Silva (1984), Cabrini et. al. (1986), Pinsky (1988) e Bittencourt (1997) em relação ao ensino da História. Assim, a reflexão sobre os critérios de construção dos fatos, a invenção das tradições nacionais e a necessidade de superar a visão eurocêntrica da História favoreceu a revisão de pressupostos teóricos e 0 trabalho com as fontes no ensino. Atualmente, as discussões em torno da temática indígena e afro-descendente na escola têm conferido suporte institucional para versões do passado opostas as que Ferro (1983) chamaria de "dos seus vencedores". Entretanto, também abrem frentes de expiação e militância na política e na sociedade como na escola. Do mesmo modo, estar às voltas com o ensino das práticas sociais no espaço importa considerar o valor operacional do estudo da Geografia e, assim, perguntar sobre os fatores sócio-políticos de ocupação do solo, de exploração das riquezas e das populações.

\section{Operações de sentido no ensino da História e da Geografia}

Não se pode deixar de reconhecer, contudo, que essa renovação das discussões sobre 0 ensino da História e da Geografia envolveu referências provenientes do próprio debate educacional. Conforme observou Dominique Borne (1998, p. 136), a mudança na maneira de ensinar História e Geografia atualmente também teve a ver com a influência de uma importante corrente pedagógica, que visava "teorizar as modalidades da aprendizagem", e que denunciou "a aula magistral", preconizando "a atividade do aluno, que deve ele próprio construir o seu saber". Ainda que assim, convém deter-se sobre o problema das condições de objetividade da História e da Geografia a fim de compreender as orientações do seu ensino como o vetor de princípios determinantes da consciência coletiva de cada sociedade. Há operações de sentido na prática do ensino dessas duas disciplinas cuja análise permite tornar inteligível o tipo de interpretação e apresentação do passado que então efetivam. Dessa perspectiva, os estudos de Ferro e Lacoste inventariam toda uma série de recursos costumeiramente utilizados para dar sentido a uma certa maneira de pensar, de fazer e de escrever a História ou a Geografia. Sua utilidade para o entendimento do protocolo de práticas do ensino das ciências humanas na

Geografia Ensino \& Pesquisa, v. 15, n.3, p. 113-128, set./dez. 2011

André Luiz Paulilo 
educação fundamental está no aparelhamento conceitual que é capaz de oferecer. Sobretudo, a análise dos artifícios da expiação, da militância ou da própria razão científica na construção histórica do passado e nas práticas geográficas pode ajudar na compreensão das tramas dessas disciplinas e no ordenamento das modalidades de sua transmissão. Trata-se de tornar as conexões entre as demandas vindas da sociedade e o trabalho do professor mais suscetíveis a avaliações.

As contribuições que as reflexões de Marc Ferro e Yves Lacoste deram ao estudo da trama epistemológica das ciências humanas abrangem diversos dos elementos do uso social e político da memória coletiva e dos espaços. Primeiro há uma especial preocupação com as sutilezas das manipulações do sentido dos fatos, da verdade histórica ou da importância estratégica das análises do espaço. Escamotear problemas, mascarar os meios da ação e seus instrumentos políticos ou deformar um tanto de pequenos episódios são práticas denunciadas como meios usuais de lidar com uma dada tradição popular ou com informações de interesse público. Alertase que na história que se conta para as crianças, como na geografia dos professores, artifícios deste tipo fazem parte das realidades que os professores tentam explicar. Em segundo lugar, Ferro e Lacoste apuram os interesses dessas manipulações, os arranjos, remodelações e acomodações que sofrem os conteúdos da História e da Geografia em conformidade com 0 poder político. Principalmente, mostram que os arranjos da verdade histórica ou da conceituação geográfica são úteis ao poder e, por vezes, resultam dos problemas de sua legitimidade. Tão importante para encarnar a teoria confucionista do "mandato celestial" na história ministrada às crianças japonesas (253) ou para as simplificações grosseiras na forma pela qual se conta a História num regime autoritário (124) quanto para iludir o papel da Geografia como instrumento de poder político (53), a seleção dos fatos e suas acomodações ideológicas ou às exigências do cidadão constituem um dos âmbitos da ação política sobre o ensino das ciências humanas. Nesse sentido, por exemplo, separar do passado aquilo que embaraça o poder do momento serve de esteio à história institucional como a recusa da reflexão epistemológica caracterizaria a geografia acadêmica na sua versão vidaliana.

Um terceiro elemento do uso social e político da memória coletiva e dos espaços analisado por Ferro e Lacoste é a postura perante a história da nação e do seu papel geopolítico. Yves Lacoste insistiu que a Geografia esconderia os problemas políticos da nação ao naturalizar "fisicamente" os fundamentos da ideologia nacional. Sobretudo atento ao enlevo patrítico da geografia ensinada nas escolas, que não corre o risco de confrontar a ideologia nacional com as contradições das realidades, Lacoste (1977, p. 32-33) adverte que a nação onde vivemos não é um dado intangível, um conjunto espacial engendrado pela natureza como fazem acreditar as análises dos espaços em escala pequena. Contradiz assim as práticas cartográficas cujo esquematismo constitui o essencial da leitura de mapas de milhões de crianças. Paralelamente, a História tem artifícios próprios para produzir o relato das derrotas e êxitos da Pátria. Ferro (1983) toma para exemplo das práticas utilizadas para reativar o passado com o objetivo de servir os objetivos nacionais do presente a revalorização do passado como forma de avaliar melhor a degradação do presente na África Negra e a valorização do presente, sua glorificação e 0 orgulho religioso no islã. Mostra de forma conveniente que tanto a hostilidade quanto a réplica à ocupação estrangeira perpetram características fundamentais na tradição historiográfica de uma nação, país ou Estado. As reflexões de Ferro e Lacoste, aliás, convergem no sentido de indicar que as noções de Estado, de país e de nação são principalmente noções políticas.

Segue um quarto conjunto de elementos. Trata-se das ações de validação das finalidades do ensino da História e da Geografia. Ferro e Lacoste apontam toda uma série de casos em que 
uma busca de sentido, explícita ou implícita, orientou o ensino da História e da Geografia de acordo com uma doutrina, ideologia ou certeza militante. As maneiras como se dá essa busca foram discutidas como práticas destinadas a legitimar o exercício do poder. Assim, por um lado, reconhece-se que há problemas correntes para o exercício do pensamento livre quando 0 ensino não adverte sobre o papel da História e da Geografia no apelo ao voluntarismo, na afirmação dos mitos de glorificação dos heróis e da Pátria e nos esforços de acepção da memória nacional. Por outro, o açambarcamento dos resultados ou meios de pesquisa por aqueles que detêm os postos de comando das organizações burocráticas ou financeiras é posto em causa. Nessa direção, tanto Ferro adverte a respeito da encarnação da história em instituições que the vergam inteira ao sabor dos regimes que controlam quanto Lacoste condena o monopólio em proveito de alguns de informações de interesse público. Não obstante reconhecerem que as instituições administrativas, financeiras e militares mantêm serviços próprios de investigação e de documentação encarregados das mais variadas tarefas, as reflexões de Ferro e Lacoste insistem que é sobretudo preciso não se deixar enganar. Saber como considerar em sua justa medida as interpretações sobre o espaço habitado e a história exige, além de uma crítica exigente dos manuais de ensino e das fontes, o respeito às precauções éticas e metodológicas elementares de uma pesquisa.

Finalmente, as práticas de constrição de sentido e invenção. Muitas das manipulações da construção história do passado e da utilidade da Geografia no ensino e nos meios de comunicação se dão por meio da omissão, das práticas de apagamento e rejeição de aspectos da memória, do resumo e erradicação de fatos e acontecimentos. Nessa via, as lições de uma história moralizadora e pregadora ou o cinismo de uma história reduzida à realpolitik permitem avaliar o quanto podem pesar as denegações e as falsificações. Do mesmo modo, a negação dos problemas que a espacialidade diferencial coloca custa uma quantidade de mistificações e de silêncios. No que concerne ao saber histórico, Marc Ferro mostra que, falando em nome de sua fé, igreja, pátria, partido ou sindicato, vencedores e vencidos da história situam-se no centro de seu respectivo mundo ao custo de iniciativas redutoras e da produção de estereótipos. De outra parte, Yves Lacoste denuncia a escamoteação do problema da escala das análises, 0 obstáculo que o conceito de região impõe à análise de outras configurações espaciais e as carências epistemológicas da Geografia como importantes recursos de ocultação e silenciamento da luta política pelo espaço. Principalmente em operações que estabelecem relações entre fenômenos humanos atestados por vestígios e sinais visíveis, as interfaces com a ética mostram-se tão fecundas quanto necessárias. Nesse campo de preocupações, a mentira, imaginada ou construída por omissão, estabelece dados maleáveis ao sabor das circunstâncias e, em geral, pretende que as grandes forças coletivas e os movimentos de longa duração têm uma importância muito secundária em relação à determinada batalha ou ato diplomático. Conforme mostram Ferro e Lacoste, o Congresso de Viena, o nazismo ou a guerra do Vietnã desenvolveram práticas específicas de mentira e, ainda atualmente, fornecem vividos exemplos de explicações forjadas, de falsificação por inversão e de pura e simples invenção. No ensino da História, como da Geografia, a construção da coerência e do sentido do discurso requer uma grande legibilidade e uma atenção sem trégua à comunicação. Daí que apurar as informações e estabelecer as suas correlações e encadeamentos define procedimentos de verificação da objetividade das práticas e metodologias do ensino.

As preocupações de Marc Ferro e Yves Lacoste com a problemática do uso social e político da memória coletiva e dos espaços desencadearam um polêmico debate sobre o ensino da História e da Geografia das escolas brasileiras. Uma evidência muito característica do interesse

Geografia Ensino \& Pesquisa, v. 15, n.3, p. 113-128, set./dez. 2011

André Luiz Paulilo 
e das motivações que as reflexões desses autores provocaram na discussão acadêmica foi a tendência crescente a ver o ensino dessas disciplinas a partir do seu conteúdo político e alcance social. $\mathrm{O}$ acumulado de pesquisas, de estudos de caso e de análises críticas mostra que atualmente a atenção dos pesquisadores do ensino de História e Geografia no Brasil incorporou das mais diversas formas essa perspectiva de abordagem nas últimas três décadas e meia. Entre os historiadores que estudaram cuidadosamente as questões de ensino, a influência das posições de Marc Ferro está presente em contribuições de exemplo, Elza Nadai (1988), Cabrini et. al. (1986), Nikitiuk (1996), Abud (1997), Macedo (2003) e Fonseca (2003). Já Yves Lacoste inspirou análises muito conseqüentes sobre o saber geográfico do aluno trabalhador (RESENDE, 1986, 1989), das relações que o ensino da Geografia manteve com o Estado autoritário no Brasil (VLACH, 1988) ou acerca do enquadramento da natureza no ensino da Geografia (CARVALHO, 1988). Esta frente de pesquisa e trabalho alcançou também a produção de livros didáticos com a tentativa de revisão das categorias de análise e, entre outras iniciativas de renovação, as propostas de uma geografia crítica ou de uma história organizada em temas.

Noutra dimensão dessas preocupações com os instrumentos de manipulação da História e da Geografia, Ferro e Lacoste se ocuparam dos meios da sua disseminação. Sobretudo, compreenderam que os veículos de comunicação também fazem da História e da Geografia uma das formas do fenômeno de consumo de massas. Segundo Lacoste (1977, p. 3 e 15), a ideologia do turismo faz da paisagem uma inesgotável fonte de inspiração para as férias tanto quanto a televisão, as revistas e os jornais dissimulam melhor ainda que o ensino o "temível instrumento de força que é a geografia para aqueles que detêm o poder". Da mesma forma, Ferro (1983, p. 138-139) avalia com pessimismo a visão de História que os meios de comunicação propõem. Mostra que os recursos atualmente utilizados para agradar a audiência na televisão ou no cinema fizeram da História "um objeto exótico, necessário, à noite, ao repouso do cidadão cansado" e, principalmente, suspeita dos seus efeitos. Como Lacoste, Ferro aborda os mass media como um discurso político impregnado de representações e de causalidades, alertando que também estes meios se valem dos artíícios de construção da verdade histórica ou das múltiplas configurações espaciais, difundindo-os inclusive. Sobretudo comentam os efeitos para o magistério desta "escola paralela" que são os meios de comunicação em massa.

Por um lado, o professor não tem mais o monopólio da informação. Atualmente, tanto o professor quanto os alunos recebem, simultaneamente, uma grande quantidade de informações históricas ou geográficas desconexas, em migalhas, de ocasião. De acordo com Lacoste (1977, p. 110), a relação pedagógica com a Geografia foi mesmo completamente modificada com a difusão espetacular das paisagens, dos mapas e dos acontecimentos físicos da Terra. Dos artifícios da moda e do espetáculo resultaram orquestrações temáticas do mesmo tipo que associam natureza e poluição ou que distinguem países desenvolvidos e subdesenvolvidos. Do mesmo modo, o ensino de história transformou-se diante do desafio dos meios de comunicação em massa. Para Ferro (1983, p. 139), concorrer com a televisão induziu os professores e os editores de livros didáticos encherem as lições com ilustrações grandes e coloridas e fazer da história ensinada uma autêntica encenação.

Por outro lado, obrigado a substituir a sua própria lição por um comentário sobre a lição dos outros, o professor pode transformar-se, perante os alunos, numa espécie de professor auxiliar. Os filmes, os jornais e as revistas já são de uso banal no ensino e os resultados não são necessariamente negativos. No entanto, campeia o populismo antiintelectualista, uma história despolitizada, a neutralização dos conflitos que é preciso lidar quando da utilização da criação

$O$ ensino do algures e do outrora: apontamentos sobre o ensino da Geografia e da História a partir das obras de Yves Lacoste e Marc Ferro 
cinematográfica e da cobertura jornalística no ensino. Dessa perspectiva, considerar essas linguagens uma panacéia para tornar o ensino mais moderno ou incorporá-las em substituição dos conteúdos de aprendizado concorre para os mesmos resultados de dissimulação ou de imposição de ideias das imagens-mensagens difundidas pelos meios de comunicação em massa. Muito por essa razão, a História e a Geografia oferecida pelo espetáculo definiu novas exigências para ambas as disciplinas.

Desde que se tornou uma opção trabalhar com diferentes gêneros discursivos no ensino da História e da Geografia, toda uma série de estudos consolidou a reflexão acerca do uso e o consumo dos diferentes meios de comunicação na sala de aula. O estudo da TV, do cinema e da fotografia reúne uma série já importante de pesquisas acerca da imagem como recurso didático do ensino. A construção dos outros que a Televisão realiza cotidianamente foi pensada por Glória da Anunciação Alves (2007) naquilo que contribui para a construção da cidade como lugar das trocas, da produção de mercadorias e do consumo. Jorge Luiz Barbosa (2007) buscou realizar no diálogo com a imagem cinematográfica um exercício de revelação da produção do espaço geográfico no cinema. Como Glória da Anunciação Alves para a TV, importou-lhe discutir os atributos objetivos da percepção do espaço nos filmes. Também ao escrever sobre a utilização das imagens na educação, Elias Thomé Saliba (1997), Marcos Silva e Selva Guimarães (2007, p. 93) mostram que o ensino de história pode se beneficiar disso explorando fatos irreais, tornados realidade porque construídos e compartilhados. Esse conjunto de estudos chama a atenção para o tratamento que o professor dá às imagens quando questiona o discurso visual. Sobretudo, insistem que trabalhar criticamente com os documentos visuais amplia 0 entendimento dos fazeres humanos, de acordo com as perguntas que professores e alunos saibam realizar. Nesse mesmo sentido, a fotografia e as exposições de museu completam as preocupações de pesquisa sobre a imagem com estudos a respeito da construção das coleções e dos discursos museológicos das exposições (ALMEIDA; VASCONCELLOS, 1997). Noutra direção, a música (SOARES, 2008), o teatro (PONTUSCHKA; PAGANELLI; CACETE, 2007) e os sítios da internet (SILVA; FONSECA, 2007) tem servido de objeto de análise para 0 desenvolvimento de outros tantos recursos didáticos e estratégias para o ensino da História e da Geografia em sala de aula. Trata-se de um esforço de compreensão das atuais demandas culturais da sociedade que certamente reconheceu no espetáculo a forma predominante de oferecer história e apresentar as paisagens às novas gerações.

\section{A educação dos viventes}

O ordenamento das modalidades de transmissão e o sentido dos problemas pedagógicos do ensino da Geografia e da História que Yves Lacoste e Marc Ferro dão aos conteúdos destas disciplinas aludem aos meios de sua manipulação. Assim, abordaram os modos de construir significados sociais e políticos através da escola. São tanto as várias interpretações de um mesmo problema quanto às práticas de falsificação ou açambarcamento do saber que thes importou questionar. Lacoste (1977) e Ferro (1983) se preocuparam, sobretudo, com as iniciativas redutoras da análise que o ensino exprime quando legitima uma política, uma ideologia ou um regime. Suas obras observam o mesmo fenômeno de empobrecimento da confiança na reflexão que o ensino da Geografia e da História impunha. Por um lado, foram criticadas as crenças e estratégias que o constituíram como um serviço que reproduz atos e

Geografia Ensino \& Pesquisa, v. 15, n.3, p. 113-128, set./dez. 2011

André Luiz Paulilo 
decisões do poder. Por outro, há uma detida reflexão acerca da estratificação das visões do passado e de compreensão do espaço. Lacoste sublinha as diferenças de propósito que permeiam a geografia dos professores, dos oficiais militares, dos exploradores, dos estadosmaiores, das grandes firmas e dos bancos como Ferro distingue as distâncias entre a história ensinada, a história problema, a história sonho e a história evasão. Principalmente nesse aspecto, entenderam que tais domínios não só traduzem diferentes combinações sociais, mas são, também, a expressão de variados sistemas de referências e de experiências.

No Brasil, as discussões em torno da importância do trabalho escolar sobre o espaço e sua representação e a respeito do passado das realidades que se tenta explicar não ignoraram essas questões. Às preocupações de Ariovaldo de Oliveira (1988) e José William Vesentini (1999) com a organização de obras interessadas em refletir o papel ideológico da geografia escolar somam-se hoje outras iniciativas. João Rua (1993) e Ana Fani Alessandri Carlos (1999; 2007) coordenaram a publicação de estudos sobre os modos como se ensina Geografia, os seus conteúdos e os instrumentos que se utilizam. Igualmente, uma profícua produção de estudos acerca do conhecimento histórico escolar se seguiu aos esforços pioneiros de Marcos Silva (1984), Conceição Cabrini (1986), Jaime Pinsky (1988) e Circe Bittencourt (1997). Nesse sentido, o ensino de História vem sendo pensado sob as mais diversas perspectivas de abordagem e segundo numerosos protocolos de investigação. Atualmente, entre outros princípios da pesquisa qualitativa, a pesquisa etnográfica (ROCHA, 2009), a pesquisa-ação (SOARES, 2008) e estudos temáticos específicos reúnem os principais resultados dos trabalhos na área do ensino da História e da Geografia. Também os manuais de Metodologia do Ensino nesse campo incluem reflexões acerca do papel ideológico do ensino da Geografia e da História, do conhecimento escolar que articulam e dos seus conteúdos e recursos. Demonstram-no, por exemplo, os manuais publicados por Bittencourt (2004), Schmidt e Cainelli (2004), Pontuschka, Paganelli e Cacete (2007) e Penteado (2008) ao lembrarem que as formas de apreensão de conceitos na escola não mudam sem a mudança da maneira de ensinar. Esses manuais, sobretudo, testemunham a atenção que hoje se dispensa ao estudo dos conteúdos do ensino e as modalidades da sua transmissão. As recentes pesquisas sobre o ensino da História e da Geografia têm-se ocupado em entender os ditames da aprendizagem do exercício do pensamento lógico, crítico e livre.

Para o ensino nas séries iniciais da educação fundamental, a leitura das obras de Yves Lacoste e Marc Ferro é especialmente útil por suas preocupações com o cego descrédito e os erros de prospectiva da Geografia e da História ensinadas nas escolas. Ainda tem a propriedade de desvelar as dificuldades que trazem consigo o ensino de uma e outra disciplina. Sobretudo por que apreender as realidades de lugares que são desconhecidos das crianças e de um passado a respeito do qual elas não possuem idéia, tentar explicar-lhes 0 algures e o outrora é sempre um empreendimento apenas conseguido de modo parcial e muito imperfeitamente. Conforme adverte André Lefebvre (1976, p. 103), "quem sobre o fato se admira ignora tudo do ofício de geógrafo e de historiador". A atenção que Lacoste e Ferro deram aos diferentes instrumentos conceituais de compreensão da Geografia e da História, como a escala na

Geografia Ensino \& Pesquisa, v. 15, n.3, p. 113-128 set./dez. 2011

0 ensino do algures e do outrora: apontamentos sobre o ensino da Geografia e da História a partir das obras de Yves Lacoste e Marc Ferro 124

ISSN 2236- 4994 cartografia e as fontes da História, contribuiu para tornar mais acessivel uma boa parte desse campo do ensino. As reflexões que a compreensão das operações de sentido no ensino da História e da Geografia e das modalidades da sua transmissão veem permitindo fazer a respeito da educação das crianças, confirmam a necessidade de levar os alunos a partilhar de um patrimônio e de uma cultura, de enraizá-los numa comunidade de memória livremente escolhida e aberta a outras solidariedades que não a da nação (cf. BORNE, 1998, p. 139-140). Ainda não 
se perderam, portanto, os ganhos da percepção histórica que Marc Ferro (1983, p. 11) expressou no início do seu livro ao escrever "Não nos enganemos: a imagem que fazemos de outros povos, e de nós mesmos, está associada à História que nos ensinaram quando éramos crianças. Ela nos marca para o resto da vida."

\section{Referências Bibliográficas}

ABUD, Kátia. Currículos de história e políticas públicas: os programas de História do Brasil na escola secundária. In.: BITTENCOURT, Circe (org.). O saber histórico na sala de aula. São Paulo: Contexto, 1997, p. 28-41.

ALMEIDA, Adriana Mortara; VASCONCELLOS, Camilo de Mello. Por que visitar museus. In.: BITTENCOURT, Circe (org.). O saber histórico na sala de aula. São Paulo: Contexto, 1997, p. 104-116.

ALMEIDA, Rosângela D. de; PASSINI, Elza Y. O espaço geográfico: ensino e representação. São Paulo: Contexto, 1989.

ALVES, Glória da Anunciação. Cidade, cotidiano e TV. In.: CARLOS, Ana Fani Alessandri (org.). A geografia na sala de aula. São Paulo: Contexto, 2007, p. 134-144.

BARBOSA, Jorge Luiz. Geografia e cinema: em busca de aproximaç̃es e do inesperado. In.: CARLOS, Ana Fani Alessandri (org.). A geografia na sala de aula. São Paulo: Contexto, 2007, p. 109-133.

BITTENCOURT, Circe. Ensino de história: fundamentos e métodos. São Paulo: Cortez, 2004. (Coleção Docência em Formação - Ensino Fundamental).

(org.). O saber histórico na sala de aula. São Paulo: Contexto, 1997.

BORNE, Dominique. Comunidade de memória e rigor crítico. In.: BOUTIER, Jean; JULIA, Dominique. Passados recompostos: campos e canteiros da História. Rio de Janeiro: UFRJ; FGV, 1998. p. 133-141.

BOURDIEU, Pierre. O poder simbólico. $3^{\mathrm{a}}$ Ed. Rio de Janeiro: Bertrand Brasil, 2000.

CABRINI, Conceição, et. al., O ensino de História (Revisão urgente). São Paulo: Brasiliense, 1986.

CARLOS, Ana Fani Alessandri (org.). A geografia na sala de aula. São Paulo: Contexto, 2007.

(org.). Novos caminhos da Geografia. São Paulo: Contexto, 1999.

CARVALHO, Marcos Bernardino de. A natureza na Geografia do Ensino Médio. In.: OLIVEIRA, Ariovaldo Umbelino (org.). Para onde vai o ensino de Geografia? São Paulo: Contexto, 1988, p. 81-108.

CAVALCANTI, Lana de Souza. Geografia, escola e construção de conhecimentos. Campinas: Papirus, 1998.

FERRO, Marc. A manipulação da história no ensino e nos meios de comunicação: a história dos dominados em todo o mundo. São Paulo: Ibrasa, 1983.

FONSECA, Selva Guimarães. Didática e prática de ensino de História. Campinas: Papirus, 2003. (Coleção Magistério: Formação e Trabalho Pedagógico).

FURTADO, Celso. Desenvolvimento e subdesenvolvimento. Rio de Janeiro: Fundo de Cultura, 1961.

GRAMSCI, Antonio. Os intelectuais e a organização da cultura. Rio de Janeiro: Civilização Brasileira, 1968.

GUNTER-FRANK, André. Capitalismo y subdesarrolo em América Latina. $3^{a}$ Ed. Buenos Aires, Siglo Veitiuno, 1974.

Geografia Ensino \& Pesquisa, v. 15, n.3, p. 113-128, set./dez. 2011

LACOSTE, Yves. A geografia serve antes de mais nada para fazer a guerra. Lisboa: Iniciativas Editoriais, André Luiz Paulilo 1977. 
Contre lês anti tiers-mondistes et contre certain tiers-mondistes. Paris : Éditions La Decouverte,

Géographie du sous développement. $3^{\text {a }}$ ed. Paris : PUF, 1976.

LEFEBVRE, André. Para uma reflexão sobre o ensino das ciências humanas no ensino elementar. In.: LEFEBVRE, André; ALLARD, Michel. A história e o seu ensino. Coimbra: Livraria Almedina, 1976, p. 87-104.

MACEDO, José Rivair. Repensando a Idade Média no ensino de História. In.: KARNAL, Leandro (org.) História na sala de aula: conceitos, práticas e propostas. São Paulo: Contexto, 2003. p. 109-125.

MOREIRA, Ruy. Assim se passaram dez anos (A renovação da geografia no Brasil- 1978-1988). In.: Caderno Prudentino de Geografia. Presidente Prudente, $n^{\circ} 14$, jun. 1992.

O discurso do avesso: para a crítica da geografia que se ensina. Rio de Janeiro: Dois Pontos, 1987.

NADAl, Elza. 0 ensino de história e a "pedagogia do cidadão". In.: PINSKY, Jaime (org.). 0 ensino de história e a criação do fato. São Paulo: Contexto, 1988, p. 27-36.

NIKITIUK, Sõnia L. (org.). Repensando o ensino de História. São Paulo: Cortez, 1996. (Questões da nossa época, 52).

OLIVEIRA, Ariovaldo Umbelino (org.). Para onde vai o ensino de Geografia? São Paulo: Contexto, 1988.

PENTEADO, Helósa Dupas. Metodologia do ensino de História e Geografia. $2^{\mathrm{a}}$ edição, São Paulo: Cortez, 2008.

PINSKY, Jaime (org.). 0 ensino de história e a criação do fato. São Paulo: Contexto, 1988.

PONTUSCHKA, Nídia Nacib ; PAGANELLI, Tomoko lyda ; CACETE, Núria Hanglei. Para ensinar e aprender Geografia. São Paulo: Cortez, 2007.

RESENDE, Márcia Spyer. A geografia do aluno trabalhador. São Paulo: Loyola, 1986.

O saber do aluno e o ensino de Geografia. In.: VESENTINI, José William (org.). Geografia e ensino. Campinas: Papirus, 1989, p. 83-116.

Revista Brasileira de História. - Órgão da Associação Nacional dos Professores Universitários de História São Paulo: ANPUH/Marco Zero, vol. 5, nº 09, set. 1985 - fev. 1986.

Revista Brasileira de História. - Órgão da Associação Nacional dos Professores Universitários de História São Paulo: ANPUH/Marco Zero, vol. 7, no 13, set. 1986 - fev. 1987.

Revista Brasileira de História. - Órgão da Associação Nacional dos Professores Universitários de História São Paulo: ANPUH/Marco Zero, vol. 9, nº 19, set. 1989 - fev. 1990.

ROCHA, Helenice Aparecida Bastos. Livros didáticos de história: a diversidade de leitores e de usos. In.: ; REZNIK, Luís; MAGALHÃES, Marcelo de Souza (org.). A história na escola: autores, livros e leituras. Rio de Janeiro: FGV, 2009, p. 201-226.

RUA, João et. al. Para ensinar Geografia. Rio de Janeiro: Access, 1993.

SALIBA, Elias Thomé. Experiências e representações sociais: reflexões sobre 0 uso e o consumo das imagens. In.: BITTENCOURT, Circe (org.). O saber histórico na sala de aula. São Paulo: Contexto, 1997, p. $117-127$.

SCHMIDT, Maria Auxiliadora; CAINELLI, Marlene. Ensinar história. São Paulo, 2004. ( Coleção Pensamento e Ação no Magistério).

SILVA, Marcos A. da (org.) Repensando a história. Rio de Janeiro: Marco Zero, 1984.

SILVA, Marcos; FONSECA, Selva Guimarães. Ensinar história no século XXI: em busca do tempo entendido. Campinas: Papirus, 2007. (Coleção Magistério: Formação e Trabalho Pedagógico).

SOARES, Olavo Pereira. A atividade de ensino de história: processo de formação de professores e alunos.

sobre o sino da Georrafia da partir das obras de Yves Lacoste e Marc Ferro 
Araraquara: Junqueira \& Marin, 2008.

VESENTINI, José William. Para uma geografia crítica na escola. São Paulo: Ática, 1992.

(org.). Ensino de geografia no século XXI. Campinas: Papirus, 2005.

(org.). Geografia e ensino. Campinas: Papirus, 1989.

VLACH, Vânia Rubia Farias. Geografia em construção. Belo Horizonte: Lê, 1991.

Ideologia do nacionalismo patrítico. In.: OLIVEIRA, Ariovaldo Umbelino (org.). Para onde vai 0 ensino de Geografia? São Paulo: Contexto, 1988, p. 39-46.

ZAMBONI, Ernesta (org.) A prática do ensino de História. São Paulo: CEDES/Cortes, 1984. (Cadernos CEDES - 10). 
Geografia Ensino \& Pesquisa, v. 15, n.3, p. 113-128, set./dez. 2011

0 ensino do algures e do outrora: apontamentos

sobre o ensino da Geografia e da História a partir das obras de Yves Lacoste e Marc Ferro

128 | ISSN 2236- 4994 